\title{
Functional data analysis of backpropagating action potentials
}

\author{
Keith J Kelleher ${ }^{1}$, Krešimir Josić ${ }^{*}$, Peter Saggau ${ }^{3}$ \\ From Nineteenth Annual Computational Neuroscience Meeting: CNS*2010 \\ San Antonio, TX, USA. 24-30 July 2010
}

Voltage propagation through neurons is a complicated process dependent on the concentrations and kinetics of ion channels, as well as the morphology of the dendrites. The task of recording the level of activation within different parts of the neuron is challenging, given the small size of the constituent structures, and the fast timescale of the signals. Recently, a fast 3D scanning microscope has been developed to address this question, with the use of fluorescent calcium indicators [1]. The resulting dataset consists of fluorescent traces from up to 50 locations with a temporal resolution upward of $1 \mathrm{kHz}$.

Our stimulation paradigms are generally trains of action potentials, initiated at the soma, which propagate backwards through the dendrites. Each back-propagating spike results in a fluorescence transient, the amplitude of which represents the relative degree of activation at each location. Our analysis of this dataset consists of two stages: First, the extraction of the amplitudes of the fluorescent transients from the noise corrupted signal. The extraction is done both by a Bayesian linear model, and more appropriately, a Sequential Monte Carlo particle filter, which takes into account the non-gaussian noise profile of the microscope's photodetector. The second phase of analysis performs the fitting of the transient amplitudes to a function representing the level of activation across the whole visible tree. To do this, we have extended existing methods in functional data analysis to branched domains. This allows the entire dataset to contribute to a single functional representation on a domain that matches the physiology of the recorded neuron.

These analysis methods, as applied to fluorescent traces from CA1 pyramidal neurons, reveal several interesting behaviors. First, we see a clear decrease in the amplitude of the fluorescence transient with distance

\footnotetext{
* Correspondence: josic@math.uh.edu

${ }^{2}$ Department of Mathematics, University of Houston, Houston, TX, 77204, USA
}

from the soma. This has been seen previously, and attributed to a decremental propagation of the spike. Second, a decrease in the distance of back-propagation with successive spikes in a train is also seen. This is attributed the slow-inactivation of sodium channels in the dendrites given repetitive activation. Furthermore, our data also shows a large effect of paired pre-synaptic stimulation in extending the range of the back-propagating spike, the magnitude and range of which is dependent on the position of the spike in the train.

\section{Author details}

1Department of Biology \& Biochemistry, University of Houston, Houston, TX 77204, USA. ${ }^{2}$ Department of Mathematics, University of Houston, Houston, TX, 77204, USA. ${ }^{3}$ Department of Neuroscience, Baylor College of Medicine, Houston, TX, 77030, USA.

Published: 20 July 2010

\section{Reference}

1. Reddy GD, Kelleher K, Fink R, Saggau P: Three-dimensional random access multiphoton microscopy for fast functional imaging of neuronal activity. Nature Neurosci 2008, 11(6):713-721.

doi:10.1186/1471-2202-11-S1-P192

Cite this article as: Kelleher et al:: Functional data analysis of

backpropagating action potentials. BMC Neuroscience 2010 11(Suppl 1): P192.

Submit your next manuscript to BioMed Central and take full advantage of:

- Convenient online submission

- Thorough peer review

- No space constraints or color figure charges

- Immediate publication on acceptance

- Inclusion in PubMed, CAS, Scopus and Google Scholar

- Research which is freely available for redistribution

Submit your manuscript at www.biomedcentral.com/submit 